\title{
The Respondent's Haptic on Academic Universities Websites of Pakistan Measuring Usability
}

\author{
Irum Naz Sodhar ${ }^{1}$, Baby Marina ${ }^{2}$, Azeem Ayaz Mirani ${ }^{3}$ \\ Post Graduate Student, Department of Information Technology \\ Quaid-e-Awam University of Engineering, Science and Technology, Nawabshah, Sindh, Pakistan
}

\begin{abstract}
This study based on survey, by using four higher educational (Universities) websites were selected for the usability testing with the help of response to the experience of eighty students of same age group and investigated to make pre-survey and post-survey based on an eight questionnaire for websites usability. The source for the survey was Laptops of windows 8.1 operation system used. The questionnaires were depends on two factors: one factor contains gender, nationality, respondents and second factor contains strongly agree, Agree, Undecided, Disagree, Strongly Disagree. The factor structure replicated across the study with data collected during usability test respectively in survey. There was evidence of usability with existing questionnaires, including the website usability testing by applying guidelines of webcredible. The overall results were acceptable and more meaningful for future researchers and webdevelopers. The questionnaire can be used to understand of websites quality and how well websites work.
\end{abstract}

Keywords-Usability testing; survey; questionnaire; higher education websites; guidelines webcredible; operating system

\section{INTRODUCTION}

\section{A. Human Computer Interaction}

Now-a-days Information Technology has reached at advanced level in every field. Human-Computer Interaction (HCI) is also one of them, which shows the communication between peoples and computers in [1]. Usability is also part of the HCI in which user define their issues related to the computer applications in [2, 3]. Design of the websites (Information Design, Navigation Design, and Visual Design), preferences, colour of the web and many other functions were checked in usability of websites in $[4,5,6]$.

\section{B. Websites}

Websites access is increasing day by day and now mostly peoples are using web to collect all kind of information such: as job advertisements, academic admissions, buy or sell products, read newspaper and so on. Author in [7] based on his research finding states that most of the users were diverse, websites were not organized in proper way according to user mentality and their wish. Users want easy and appropriate response from web sites they use for their purpose. Many design rules are available in literature to increase the usability on different domain. Authors in [8] worked on the educational websites and designed survey for the measurement of satisfaction of college websites users. Authors found $89.4 \%$ satisfaction ratio of the user team and they strongly agree on the college websites in [9].

\section{Usability}

Usability is a technique used to identify about the idea of users regarding websites by applying usability technique website how to work and find out errors where were occur in websites. Fig. 1 show the usability components and seven usability components which are following.
1) Navigation
2) Familiarity
3) Consistency
4) Error Prevention
5) Feedback
6) Visual Clarity
7) Flexibility and Efficiency

\section{Usability Guidelines}

Usability and accessibility of university website of Malaysia and used automatic evaluation by using WCAG 1.0 guidelines provide five steps to conducted research as under below in [9].

- One step is called by: Themes of accessible of design.

- Second step is called by: How the things are organized.

- Third step is called by: Check Priority Level.

- Fourth step is called by: Conformance of the documents.

- Fifth step is called by: Web contents Accessibility guidelines. The guidelines available are 14 present to access web contents which are:

- Visual Contents on websites.

- Don not rely on colour.

- Use mark-up and style sheets.

- Clarify the language usage.

- Create tables that transform gracefully.

- Support multiplatform or Ensure that pages featuring new technologies transform gracefully.

- Ensure user control of time-sensitive content changes.

- Direct accessibility of embedded user interfaces.

- Design for device-independence. 
- Use interim solutions.

- Follow the W3C guidelines.

- Provide informative Context.

- Provide clear navigate mechanism.

- Documents should be clear and simple.

There are many methods available for the usability testing such as novel cross-sequential method, cross-sectional method, longitudinal method, Retrospective method and Nielsen heuristics method [10] as shown in Fig. 2. Nielsen heuristics method is one of the appropriate methods for post-survey techniques in [11-14], before the post-survey, it is important to use pre-survey method for the testing usability of websites. From this type of survey issues related to the websites and users are identified, accordingly, these issues may be addressed in search, navigation and information required to the users in $[6,15]$.

Interaction of humans with computer is increased day by day. Due to increase of attention on computers by the majority of peoples (students) using search or getting information regarding education, jobs and news updates from educational websites, but they face many issues and problem. Survey is the best method to identify the issues/problems of computer users.

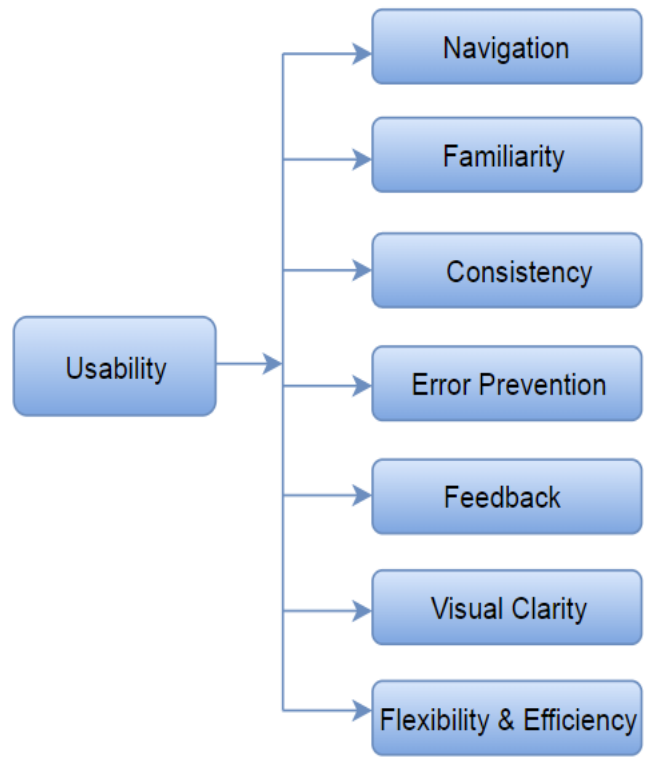

Fig. 1. Usability Snapshot.

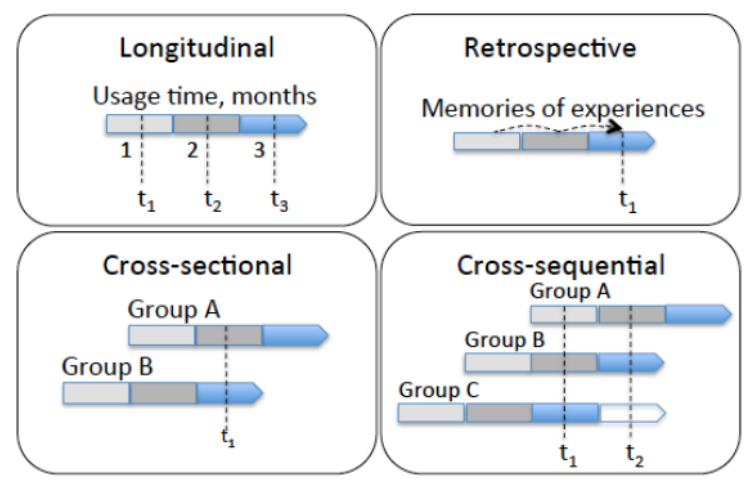

Fig. 2. Survey Methods for Measuring usability [10].

\section{UsABILITY TeSTING BY USING SURVEY METHOD}

Internet is the source in which usability testing is evaluated and find out all the parameters of usability [14]. The process of usability testing of engineering university websites of SindhPakistan is shown in Fig. 3. In this figure process of collection of data, based on the selected websites of engineering universities as described in Table $\mathrm{I}$ is given. These four universities are the top ranked government universities of Sindh province in and Pakistan. Majority of engineering students' are studies in these universities. These engineering students and job seekers are using these websites on daily basis to check universities information and news, advertisements for jobs, admissions, results and other purposes.

In this study, experimental survey was carried out in two phases, one is pre-survey and other is post-survey. Pre-survey gives information of respondents (detailed information of respondents is shown in Table III). The same is used in postsurvey. Following are the Pre-survey questionnaires was designed $[6,16]$ and details of these questionnaires are given in Table II.

1) What is your gender?

2) How old are you?

3) What is your nationality?

Eighty numbers of respondents were selected for this of survey. All respondents were of age group between 18 years to 25 years. All eighty respondents were the students of 3rd years in Bachelor of Science (Information Technology). Out of eighty respondents, 18 respondents were females and others were the male students. All respondents have same nationality (Pakistani) and belong to province of Sindh.

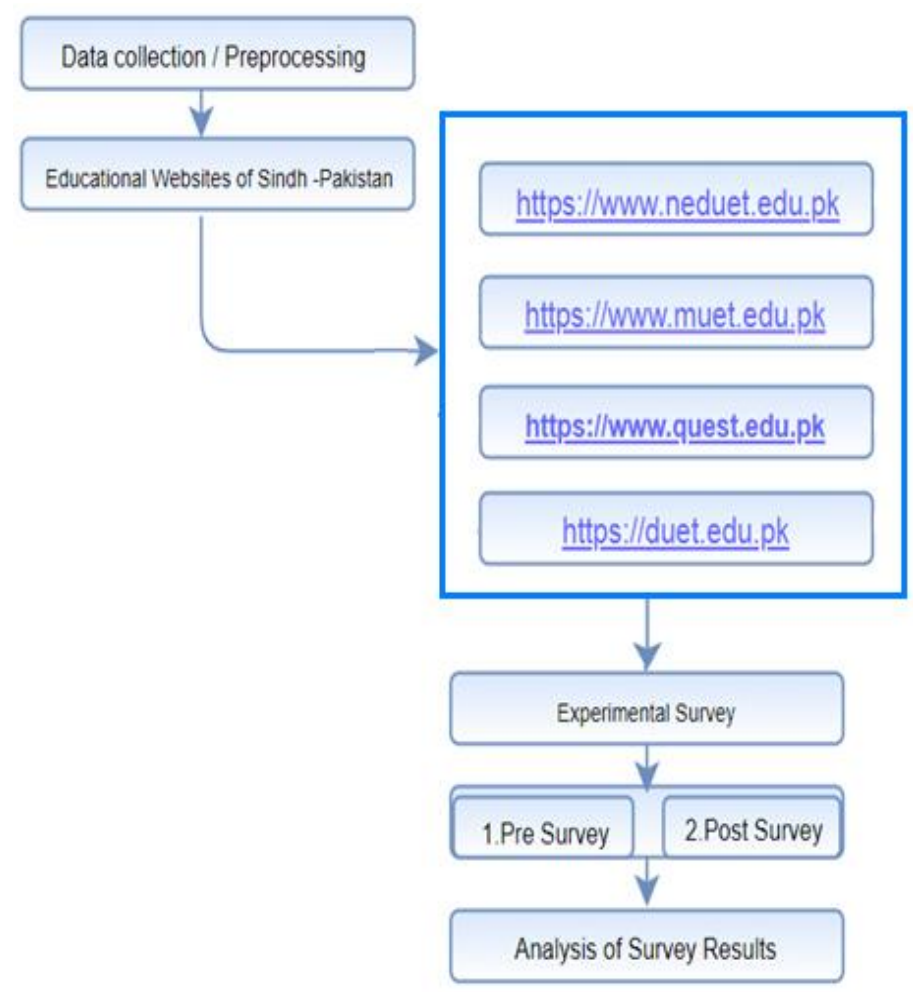

Fig. 3. Research Methodology. 
TABLE. I. EDUCATIONAL WEBSITES OF ENGINEERING UNIVERSITIES OF SINDH

\begin{tabular}{|l|l|l|}
\hline S. No & Name of University & University Websites \\
\hline 1 & NED University of Engineering \& Technology, Karachi & https://www.neduet.edu.pk \\
\hline 2 & Mehran University of Engineering and Technology Jamshoro. & https://www.muet.edu.pk \\
\hline 3 & Quaid-e-Awam University of Engineering, Science \& Technology, Nawabshah. & https://www.quest.edu.pk \\
\hline 4 & Dawood University of Engineering \& Technology Karachi. & https://duet.edu.pk \\
\hline
\end{tabular}

TABLE. II. PRE-SURVEY-QUESTIONS

\begin{tabular}{|l|l|l|l|l|}
\hline Questions & Male & Female & Nationality & Respondents \\
\hline What is your gender? & 62 & 18 & Pakistani & 80 \\
\hline How old are you? & Between (18-25) & Between (18-25) & Pakistani & 80 \\
\hline What is your Nationality? & 62 & 18 & Pakistani & 80 \\
\hline
\end{tabular}

TABLE. III. RESPONDENTS DETAILS OF AGE GROUP 18-25 YeARS

\begin{tabular}{|c|c|c|c|c|c|c|c|}
\hline S.N. & Respondents Name & Study Year & Gender & S. No. & Respondents Name & Study Year & Gender \\
\hline 1 & Anjum & 3rd year & Female & 41 & Muneer Ahmed & 3rd year & Male \\
\hline 2 & Nida Sehar & 3rd year & Female & 42 & Saeed Ahmed & 3rd year & Male \\
\hline 3 & Farzana & 3rd year & Female & 43 & Adnan Eijaz & 3rd year & Male \\
\hline 4 & Chandini & 3rd year & Female & 44 & Muhammad Awais & 3rd year & Male \\
\hline 5 & Laila & 3rd year & Female & 45 & Mohammad Yousif & 3rd year & Male \\
\hline 6 & Aneela & 3rd year & Female & 46 & Ubaid & 3rd year & Male \\
\hline 7 & Aisha & 3rd year & Female & 47 & Nisar Ali & 3rd year & Male \\
\hline 8 & Ameena & 3rd year & Female & 48 & Ashraf & 3rd year & Male \\
\hline 9 & Poonam & 3rd year & Female & 49 & Muhammad Suleman & 3rd year & Male \\
\hline 10 & Dua Noor & 3rd year & Female & 50 & Kashif Ali & 3rd year & Male \\
\hline 11 & Ilham khan & 3rd year & Female & 51 & M.Farman & 3rd year & Male \\
\hline 12 & Humaira & 3rd year & Female & 52 & Sajjad Hussain & 3rd year & Male \\
\hline 13 & Iqra & 3rd year & Female & 53 & Muhammad Aamir Noor & 3rd year & Male \\
\hline 14 & Maheen & 3rd year & Female & 54 & Haseeb Aziz & 3rd year & Male \\
\hline 15 & Nimra & 3rd year & Female & 55 & Bilal Khan & 3rd year & Male \\
\hline 16 & Erum Muneer & 3rd year & Female & 56 & Muhammad Zeeshan & 3rd year & Male \\
\hline 17 & Syeda Fizza & 3rd year & Female & 57 & Manthar Ali & 3rd year & Male \\
\hline 18 & Nigarish & 3rd year & Female & 58 & Abdul Nabi & 3rd year & Male \\
\hline 19 & Baqir Ali & 3rd year & Male & 59 & Jazib Bilal & 3rd year & Male \\
\hline 20 & Allah Warayo & 3rd year & Male & 60 & Abdul Samad & 3rd year & Male \\
\hline 21 & Muhammad Baig & 3rd year & Male & 61 & Shahbaz Qureshi & 3rd year & Male \\
\hline 22 & Saifullah & 3rd year & Male & 62 & Muhammad Awais Noori & 3rd year & Male \\
\hline 23 & Noshad Ali & 3rd year & Male & 63 & M.Rajab Ali & 3rd year & Male \\
\hline 24 & Vinod Kumar & 3rd year & Male & 64 & Abdul Hafeez & 3rd year & Male \\
\hline 25 & Muhammad Muneeb & 3rd year & Male & 65 & Muhammad Adeel & 3rd year & Male \\
\hline 26 & Naseer Ahmed & 3rd year & Male & 66 & Usama Jabbar & 3rd year & Male \\
\hline 27 & Saifullah Unar & 3rd year & Male & 67 & Zubair Akram & 3rd year & Male \\
\hline 28 & Abdul Sallam & 3rd year & Male & 68 & Sadam Hussain & 3rd year & Male \\
\hline 29 & Shakeeb Nasir & 3rd year & Male & 69 & Sajjad Ali & 3rd year & Male \\
\hline 30 & Shahzaib & 3rd year & Male & 70 & Anil & 3rd year & Male \\
\hline 31 & Zafar Ali & 3rd year & Male & 71 & Awais Kareem & 3rd year & Male \\
\hline 32 & Muhammad Anwar & 3rd year & Male & 72 & Farhan Brohi & 3rd year & Male \\
\hline 33 & Danish & 3rd year & Male & 73 & Zubair & 3rd year & Male \\
\hline 34 & Mohammad Waqqar & 3rd year & Male & 74 & Mehran & 3rd year & Male \\
\hline 35 & Tanveer Hussain & 3rd year & Male & 75 & Abid Ali & 3rd year & Male \\
\hline 36 & Bilal & 3rd year & Male & 76 & Ali Haider & 3rd year & Male \\
\hline 37 & Taimoor Ahmed & 3rd year & Male & 77 & Bilal & 3rd year & Male \\
\hline 38 & Hassan Zaib & 3rd year & Male & 78 & Saeed Rasool & 3rd year & Male \\
\hline 39 & Hamza & 3rd year & Male & 79 & Masood Ali & 3rd year & Male \\
\hline 40 & Mohammad & 3rd year & Male & 80 & M.Faizan & 3rd year & Male \\
\hline
\end{tabular}


TABLE. IV. POST-SURVEY-QUESTIONS

\begin{tabular}{|c|c|c|c|c|c|}
\hline Questions & SA & $\mathbf{A}$ & UD & D & SD \\
\hline The site was easy to Navigate? & 44 & 28 & 6 & 2 & Nil \\
\hline This site answered my questions? & 12 & 52 & 12 & 4 & Nil \\
\hline I would like to visit this site again? & 12 & 28 & 36 & 4 & Nil \\
\hline $\begin{array}{l}\text { I would like to recommend this site } \\
\text { to my friend? }\end{array}$ & 24 & 44 & 10 & 2 & Nil \\
\hline $\begin{array}{l}\text { Are you satisfied from this site } \\
\text { visit? }\end{array}$ & 14 & 54 & 9 & 3 & Nil \\
\hline SA & $=$ & \multicolumn{4}{|c|}{ Strongly Agree } \\
\hline A & $=$ & \multicolumn{4}{|c|}{ Agree } \\
\hline UD & $=$ & \multicolumn{4}{|c|}{ Un-decided } \\
\hline D & $=$ & \multicolumn{4}{|c|}{ Disagree } \\
\hline SD & $=$ & \multicolumn{4}{|c|}{ Strongly disagree } \\
\hline
\end{tabular}

In Post-survey, an experimental procedure for the finding the usability issues related to websites is adopted. In this research work navigation related information, recommendations and satisfactions were studied for the usability testing. From the selected respondents forty four respondents were strongly agreed for the easy navigation of the websites and twenty eight showed agreed with the navigation but few of them were not clear (undecided) for navigational capabilities as described in Table IV.

Websites of engineering universities of Sindh-Pakistan used in this experimental survey had sufficient information for the majority of the users and they agreed that they found their information/news from the web but many of the respondents were undecided and were of the opinion that they would not like to visit again for information/news they require. Those who they showed satisfaction also stated that they will recommend these websites to their friends for useful information available and also majority of the respondents were satisfied from these websites.

Design methodology was divided in to four parts as shown in Fig. 2. First of all it was necessary to collect/select the data and then comes 2 nd part of the methodology which also known as boundary lines of the research. After the deciding of boundary lines or limitation then it comes in 3rd round which is experimental survey and this survey was analysed in different ways.

\section{RESULTS AND DISCUSSIONS}

Post-survey is a technique used for the testing of usability of websites. In this study this technique was used for testing usability of websites of engineering universities of SindhPakistan. Four university websites were selected. From the survey it was observed that many respondents strongly agreed as shown in Fig. 4(a-e).

In Fig. 5 comparison of post survey questionnaires are presented. In this comparison majority of respondent were agreed to visit these site again, but they highlight the problem of navigation and they need to improve this issue and also related feathers.

From the experimental study most of the frequent issues were addressed by respondent by using usability testing techniques for websites of engineering universities. Almost all the websites had issues like size, font, and animation as described in Table V. Majority of websites did not update on daily basis and information/news regarding users was not enough. Website of NED University of Engineering \& Technology, Karachi lacks back to home page option directly from deep navigated pages. Also same issue in Website of Mehran University of Engineering and Technology Jamshoro was observed.

TABLE. V. MOST FREQUENT USABILITY ISSUES

\begin{tabular}{|c|c|}
\hline Engineering University & Most frequent usability Issues \\
\hline $\begin{array}{l}\text { NED University of } \\
\text { Engineering \& } \\
\text { Technology, Karachi }\end{array}$ & $\begin{array}{l}\text { - Not available home page option in links of } \\
\text { different pages. } \\
\text { - } \quad \text { Font size, style and colors issue. } \\
\text { - } \quad \text { Inimation problem. } \\
\text { - Improperly managed information/news. } \\
\text { Information regarding previous, current and } \\
\text { future projects of the study programs was } \\
\text { not updated. }\end{array}$ \\
\hline $\begin{array}{l}\text { Mehran University of } \\
\text { Engineering and } \\
\text { Technology Jamshoro }\end{array}$ & $\begin{array}{l}\text { Quick Search option was not working } \\
\text { properly and takes more time for searching. } \\
\text { - } \quad \text { Improper management information/news. } \\
\text { Animations on main page were very high } \\
\text { for all news and it may increase mental } \\
\text { stresses. } \\
\text { Information regarding previous, current and } \\
\text { future projects of the study programs was } \\
\text { not updated. }\end{array}$ \\
\hline $\begin{array}{l}\text { Quaid-e-Awam University } \\
\text { of Engineering, Science \& } \\
\text { Technology, Nawabshah }\end{array}$ & $\begin{array}{l}\text { - Current information/news was not updated. } \\
\text { - Information regarding previous, current and } \\
\text { future projects of the study programs was } \\
\text { not updated. }\end{array}$ \\
\hline $\begin{array}{l}\text { Dawood University of } \\
\text { Engineering \& Technology } \\
\text { Karachi }\end{array}$ & $\begin{array}{l}\text { - Improve layout of the Site. } \\
\text { - } \quad \text { Font size, style and colors issue. } \\
\text { Information regarding previous, current and } \\
\text { future projects of the study programs was } \\
\text { not updated. }\end{array}$ \\
\hline
\end{tabular}




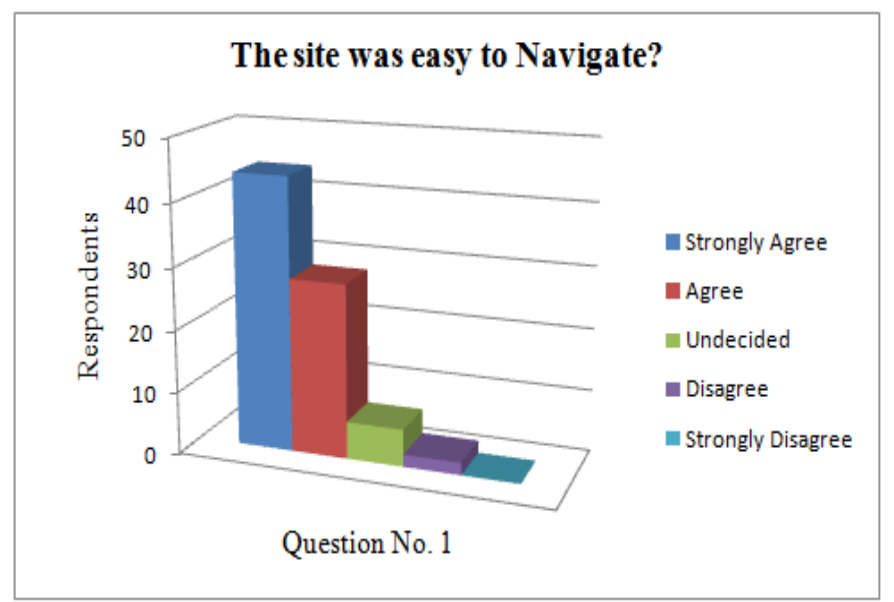

(a)

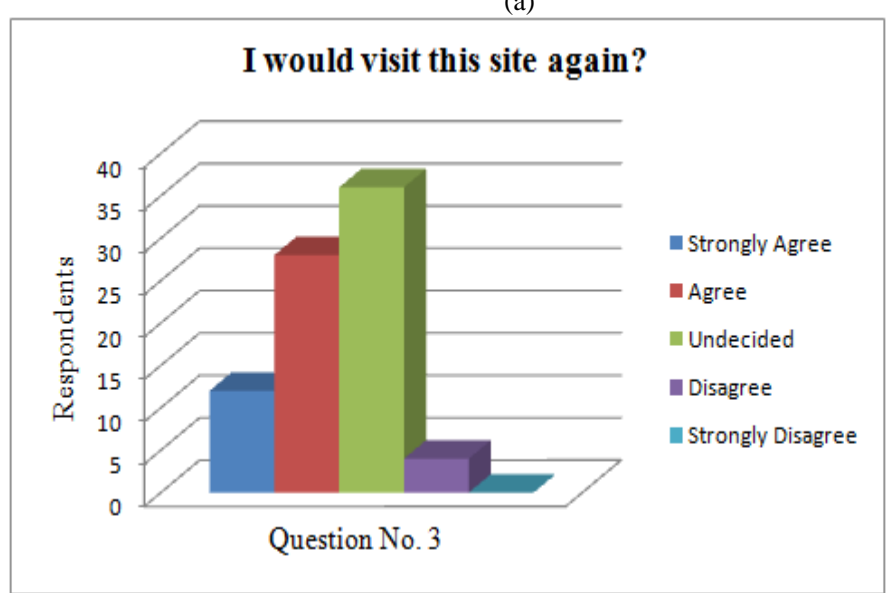

(c)

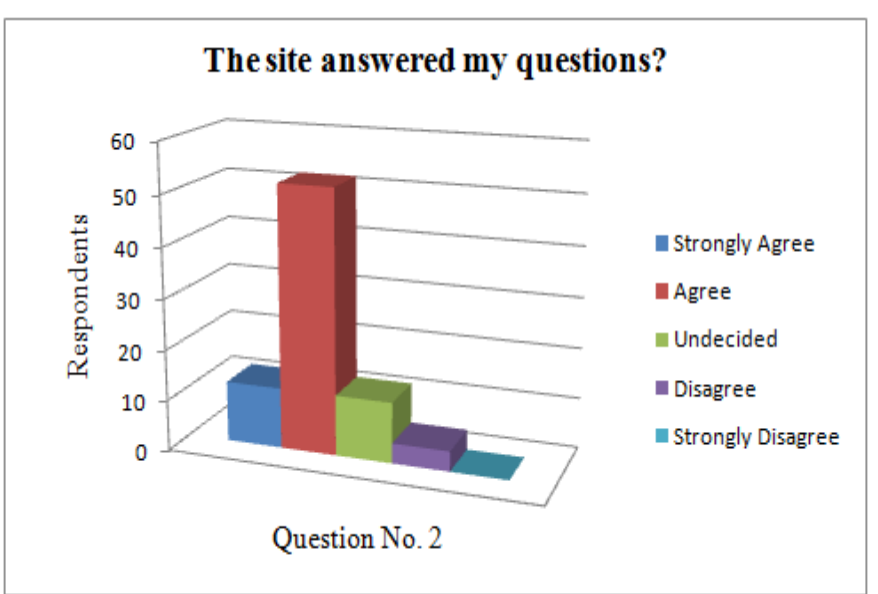

(b)

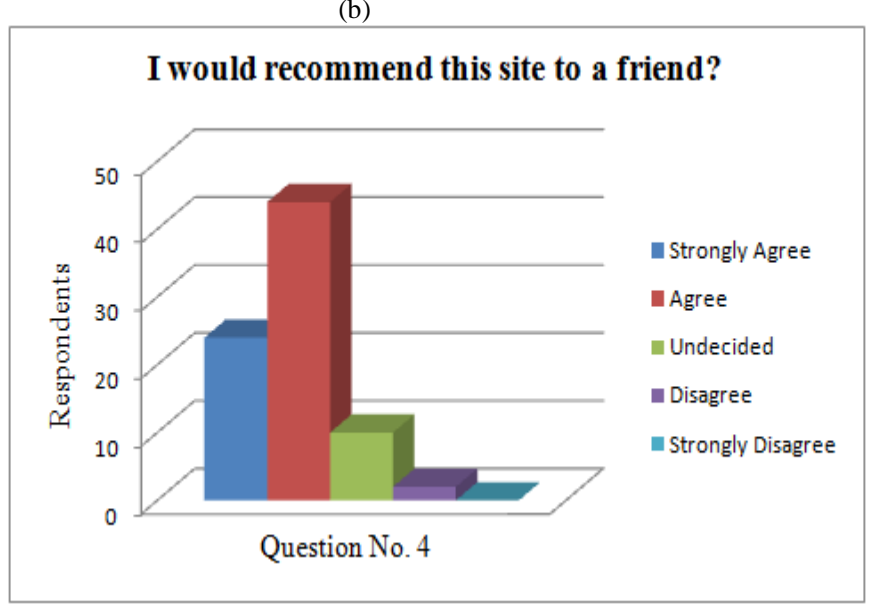

(d)

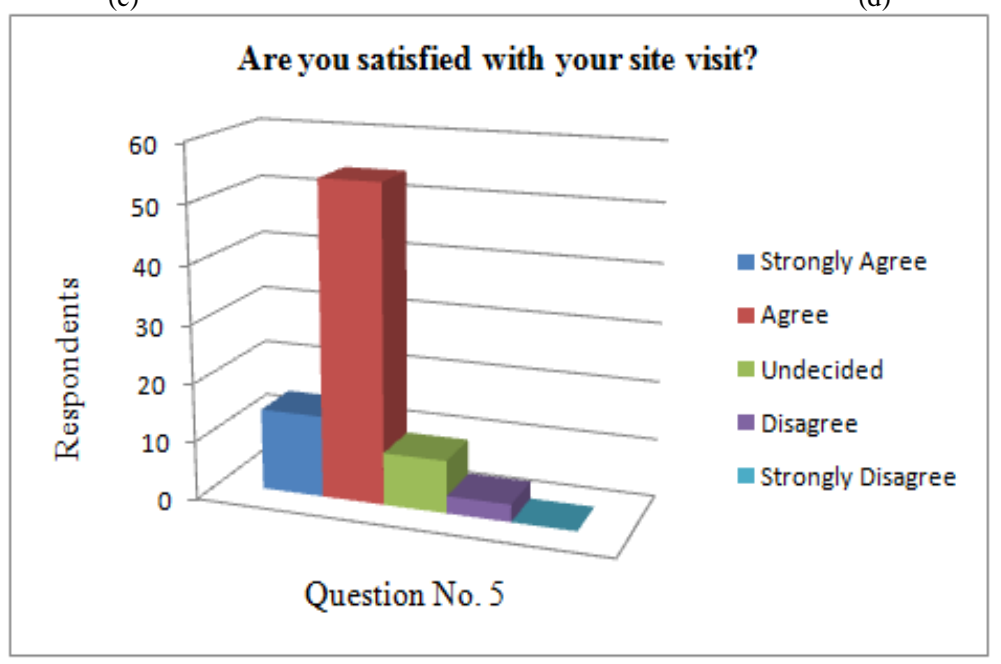

(e)

Fig. 4. Graphical Representation of Post-Survey Questionnaires (a) to (e). 


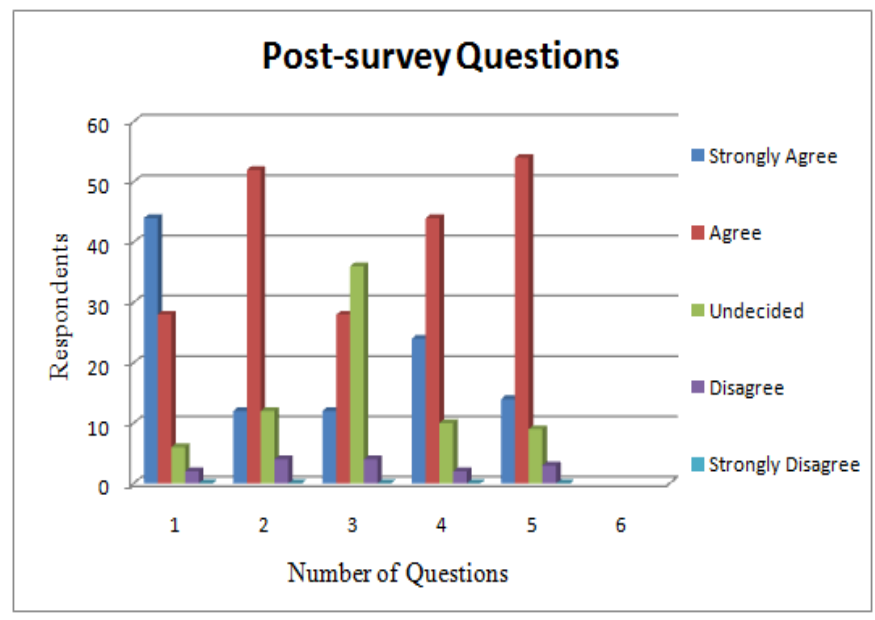

Fig. 5. Comparison of Post-Survey Questionnaires.

\section{CONCLUSION}

The results suggest that the Nielsen heuristics method is useful in identifying the issues related to the usability of educational websites. This study gives an idea about the usability issues at different levels of website. Websites gives information/news related to users but these websites have many issues like; proper update on daily basis, page layout, font size and style, colours and lots of links available on sites. It is also observed that Information regarding previous, current and future projects of the study programs was not updated. Quick Search option was not working properly and takes more time for searching and improper management information/news. This research provides issues in educational websites which are mostly used by the students. University should take follow this type of survey results and improve their websites for above survey results.

\section{FUTURE WORK}

In future researchers paid more attention to the usability of websites in different domains.

\section{REFERENCES}

[1] C. Dianne, H. Milena, and H. Larios, "Colour appeal in website design within and across cultures: A multi-method evaluation," International journal of human-computer studies, Vol. 68, No. 1-2, pp. 1-21, 2010.

[2] Nawaz, Ather, and T. Clemmensen, "Website usability in Asia "from within": an overview of a decade of literature," International Journal of Human-Computer Interaction Vol. 29, No. 4, pp. 256-273, 2013.

[3] C. Dianne, "Website design, trust and culture: An eight country investigation,"Electronic Commerce Research and Applications, Vol. 12, No. 6, pp. 373-385, 2013.

[4] Lazar, Jonathan, J. H. Feng, and H. Hochheiser, "Research methods in human-computer interaction," Morgan Kaufmann, 2017.

[5] Interaction Design Foundation, https://www.interaction- design.org/ literature/article /an-introduction-to-usability.

[6] I. Oakley-Girvan, J. M. Lavista, Y. Miller, S. Davis, A. Carlos, J. Hancock, and L. M. Nelson, "Evaluation of a Mobile Device Survey System for Behavioral Risk Factors (SHAPE): App Development and Usability Study," JMIR formative research, Vol. 3, No. 1, 2019.

[7] S. Nizamani, K. Khoumbati, S. Nizamani, S. Memon, and S. Nizamani, "Usability evaluation of the top 10 Universities of Pakistan through Guideline Scoring," Sindh University Research Journal-SURJ (Science Series), Vol. 51, No. 01, pp.151-158, 2019.

[8] S. Christoun, H. Aubin, C. Hannon, R. Wolk, "Web site usability in higher education," Director. 2006:07. Dec. 2010.

[9] Saeed, Saqib, and A. Amjad, "Understanding usability issues of Pakistani university websites," Life Science Journal, Vol:10, No. 6, pp. 479-482, 2013.

[10] Kujala, Sari, T. Miron-Shatz, and J. J. Jokinen, "The Cross-Sequential Approach: A Short-Term Method for Studying Long-Term User Experience," Journal of Usability Studies, Vol. 14, No. 2, 2019.

[11] Super User Friendly "Usability Testing Survey Template" https://sites.google.com/site/superuserfriendly/templates/usabilitytesting-survey-template.

[12] Ashraf, Mahmood, L. Khan, M. Tahir, A. Alghamdi, M. Alqarni, T. Sabbah, and M. Khan, "A study on usability awareness in local IT industry," Int. J. Adv. Comput. Sci. Appl, Vol. 9, pp. 427-432, 2018.

[13] Bhatt, Siddharth, A. Agrali, K. McCarthy, R. Suri, and H. Ayaz, "Web Usability Testing With Concurrent fNIRS and Eye Tracking," In Neuroergonomics, pp. 181-186, 2019.

[14] Rzeszewski, Michal, and J. Kotus, "Usability and usefulness of internet mapping platforms in participatory spatial planning," Applied geography, Vol. 103, pp. 56-69, 2019.

[15] Daniel, A. Olujimi, A. Oludele, R. Baguma, and T. Weide, "Cultural issues and their relevance in designing usable websites." (2011).

[16] Root, W. Robert, and S. Draper, "Questionnaires as a software evaluation tool," In Proceedings of the SIGCHI conference on Human Factors in Computing Systems, pp. 83-87. ACM, 1983. 